\title{
POLÍTICAS PÚBLICAS E TRATAMENTO DA CRIMINALIDADE NUMA SOCIEDADE DEMOCRÁTICA
}

\author{
André Leonardo Copetti Santos ${ }^{1}$
}

\section{RESUMO}

O presente artigo busca estabelecer algumas bases políticas indicativas do que pode ser considerada uma intervenção estatal democrática, adequada a um país emergente, para o enfrentamento do problema da criminalidade, a partir do projeto de sociedade, Estado e Direito positivado constitucionalmente em 1988.

Palavras-chave: Constituição. Democracia. Estado Democrático de Direito. Políticas públicas. Prevenção criminal.

\section{INTRODUÇÃO}

O estabelecimento de alguns fundamentos políticos para a articulação de políticas públicas de combate à criminalidade, a partir do binômio constituído pela realidade concreta do fenômeno criminal no Brasil e pelas indicações formais constitucionais da atuação do Estado, compõe o principal desiderato do presente trabalho.

Inexiste aqui qualquer pretensão de exaurimento do tema ou de apresentação de fórmulas dogmáticas penais prontas e acabadas que venham a conduzir, inexoravelmente, os processos hermenêuticos de penalistas e criminólogos dedicados à política criminal ou à renovação dogmática do direito penal, face às demandas substanciais dadas pela realidade e pelo novo sistema normativoaxiológico constitucional. O que se busca é a fixação de uma direção política democrática a ser efetivamente assumida pelo Estado em seus objetivos de enfrentamento da criminalidade.

Os caminhos do texto são mais zetéticos do que propriamente dogmáticos, o que não significa que não se esteja empenhado na busca do estabelecimento de algumas definições de natureza prescritiva para o direcionamento do sistema normativo sancionatório e de natureza política para a atuação estatal no tratamento do problema da crimnalidade.

\section{A COMPLEXIDADE CONSTITUCIONAL E OS ESTÍMULOS DEMOCRÁTICOS DA ATUAÇÃO POLÍTICO-CRIMINAL}

Com o deslocamento do centro de gravidade dos princípios orientadores do Estado de Direito, desde uma configuração formal - individualista, típica do Estado liberal, até uma perspectiva material-coletivista, característica do Estado social e, posteriormente, com a fusão dessas duas lógicas no modelo constitucional de Estado Democrático de Direito, que as supera, na medida em que sua funcionalidade não se restringe à agregação das duas anteriores, de forma 
fragmentada e estanque, mas a elas adiciona objetivos transformadores, algumas novas situações problemáticas se colocaram em relação à definição, extensão e funcionalidade do direito penal e, por consequência, sobre as diretrizes políticocriminais que devem ser adotadas para o enfrentamento do problema da criminalidade.

Na medida em que foram redefinidos constitucionalmente, sem maior precisão, os espaços individuais e não-individuais e, também, em função disso, as possibilidades de intervenção do Estado, passou a haver a necessidade de rediscussão acerca das medidas político-criminais que melhor se ajustem a um modelo de Estado Democrático de Direito que deve ser aplicado a um país périférico como o Brasil.

Nessa busca, é preciso levar em conta um quadro sócio-histórico extremamente complexo. Por um lado, as liberdades individuais foram fustigadas em um período autoritário recente e, portanto, não é recomendável, para qualquer projeto democrático, o afrouxamento destas tutelas fundamentais. Pelo contrário, precisam ser amplamente garantidas. Por outro, há de se considerar que no Brasil há, ainda, uma imensa massa de miseráveis, locus principal de proliferação de novos criminosos, razão pela qual persistem as demandas de concretização de políticas sociais, o que constitui caminho inexorável de qualquer percurso histórico de evolução civilizatória de um país rumo a uma democracia substancialmente considerada. Se tais situações não fossem já suficientes para complexificar a reflexão sobre políticas criminais adequadas a uma sociedade democrática, ainda não se pode olvidar que a criminalidade no Brasil tem se reproduzido significativamente, e isto tem gerado um grande apelo social a um direito penal cada vez mais repressor. A tudo isto ainda é preciso agregar que qualitativamente o fenômeno criminal no Brasil assume características muito particulares, onde a criminalidade tradicional não recua um só milímetro, pelo contrário, avança, convivendo, lado a lado, com uma criminalidade organizada cujos interesses estão voltados não aos tráficos em geral, mas também lança seus soldados em direção ao patrimônio público.

O ponto de partida de qualquer redefinição político-criminal deve considerar, num Estado Democrático de Direito, dentre outros elementos, a estrutura axiológiconormativa que dá base a toda concretude operacional do Direito. Nesse aspecto, a Constituição Federal de 1988 representou uma guinada em relação à toda histórica constitucional no Brasil. Essa transição paradigmática axiológica-normativa implica, por um lado, em um projeto de liberdade e de segurança individual do cidadão, e, por outro, de garantia de seus espaços materiais individuais e de realização de uma democracia social que pressupõe a aproximação de um ideal de igualdade substancial dentro de uma perspectiva de pertencimento a uma comunidade que aspira ao bem comum e que, por isso, não deve ocorrer somente através da abstenção do Estado, mas com a garantia positiva, a cargo deste, de uma existência digna do ser humano. Esta perspectiva na pode ser desdenhada quando se fala em políticas criminais em um Estado Democrático e Social de Direito, no qual não há uma liberdade de conformação do legislador, mas uma vinculação ao projeto constitucional, cuja complexidade contempla tutela ao indivíduo e guarida ao âmbito de direitos e interesses não-individuais, além de prodigamente prever proteções a especificidades culturais. 
Nesse sentido que Canotilho fala da "força dirigente dos direitos fundamentais" e as implicações dessa concepção nas funções estatais, reforçando que:

\begin{abstract}
[...] a força dirigente e determinante dos direitos a prestações (econômicos, sociais e culturais) inverte, desde logo, o objeto clássico da pretensão jurídica fundada num direito subjetivo: de uma pretensão de omissão dos poderes públicos (direito a exigir que o Estado se abstenha de interferir nos direitos, liberdades e garantias) transitase para uma proibição de omissão (direito a exigir que o Estado intervenha ativamente no sentido de assegurar prestações aos cidadãos). A "polemização" dos fundamentos do Estado é também patente: os direitos a prestações suscitam a discussão do tipo de Estado (capitalista, socialista) que melhor os pode assegurar; pressupõem uma tarefa de conformação social activa por parte dos poderes públicos, sobretudo do legislador; reclamam nova distribuição de bens e rendimentos, e, até, uma transformação social de estruturas econômicas. ${ }^{2}$
\end{abstract}

Com isso, quer-se aqui dizer que a idéia de uma proposta de política criminal adequada a país como Brasil, que hoje já deixou de ser internacionalmente qualificado como subdesenvolvido, em desenvolvimento, de terceiro mundo ou periférico, para ser adjetivado de emergente, pressupõe uma vinculação do legislador ao binômio sistema normativo constitucional abstrato/problemas concretos da realidade social. Não há de se falar aqui de liberdade de conformação do legislador penal. Este sofre as imposições e exigências decorrentes do binômio antes referido, devendo sua atuação estar voltada à realização do projeto contido na Carta Constitucional, pois nele está encerrado uma concepção de bem, de justiça social e, em última análise, de felicidade. Nesse sentido, lapidares são as palavras de Streck, que entende, na esteira da proporcionalidade, que:

\begin{abstract}
[...] não há liberdade (absoluta) de conformação legislativa nem mesmo em matéria penal, ainda que a lei venha a descriminalizar condutas consideradas ofensivas a bens fundamentais. Nesse sentido, se de um lado há a proibição de excesso (Ubermassverbot), de outro há a proibição de proteção deficiente (Untermassverbot). Ou seja, o direito penal não pode ser tratado como se existisse apenas uma espécie de garantismo negativo, a partir da garantia de proibição de excesso. Com efeito, a partir do papel assumido pelo Estado e pelo Direito no Estado Democrático de Direito, o direito penal deve ser (sempre) examinado também a partir de um garantismo positivo, isto é, devemos nos indagar acerca do dever de proteção de determinados bens fundamentais através do direito penal. ${ }^{3}$
\end{abstract}

Algumas questões prévias são inevitáveis considerar. Em primeiro lugar, é preciso tomar em conta o fracasso histórico do modelo repressivo clássico da modernidade, consistente no inflição de castigos à alma mediante as penas privativas de liberdade. A comunidade científica não possui mais qualquer dúvida sobre a escassa efetividade e sobre os elevados custos sociais deste modelo, com irrisórios e desproporcionais benefícios em relação aos males causados aos indivíduos. Esse modelo tem chegado sempre mal e sempre tarde para o tratamento do fenômeno criminal, pois ao confundir política penal com política criminal e ao tratar do efeito e não da causa, firma definitivamente sua incapacidade e inefetividade para tal tarefa social. Há uma incapacidade congênita da prisão em exercer efeito positivo qualquer sobre a criminalidade.

Em segundo lugar, como observa Pablos de Molina, se o crime não é um fenômeno causal, fortuito ou aleatório, produto do azar ou da fatalidade, mas um 
acontecimento altamente seletivo, a existência de informações empíricas confiáveis sobre as principais variáveis desse fenômeno abre imensas possibilidades de adoção de políticas criminais eficazes. ${ }^{4}$

Não há dúvidas que na evolução secularizada do Estado de Direito, do paradigma liberal ao Democrático de Direito, houve uma paulatina redução das liberdades individuais em decorrência da ampliação dos espaços de intervenção estatal, situação que confirma a anotação de Benda ao referir que é:

[...] consecuencia ineludible del mandato del Estado social hacer posible una compensación adecuada de intereses, que nunca pode significar libertad absoluta, sino tan sólo la garantia justa de un espacio suficiente de libertad para cada cual. De ahí que sea comprensible que, a juicio de los afectados, el Estado social comporte también una reducción de la libertad. ${ }^{5}$

Esse foi o percurso histórico das políticas de combate à criminalidade nos Estados de Direito ocidentais, com uma clara opção política pela intervenção estatal penal em detrimento de políticas públicas não penais de enfrentamento da criminalidade. A repercussão disto foi que ampliou-se inflacionariamente o direito penal e proporcionalmente reduziram-se garantias.

Entretanto, é preciso considerar que a redução da autonomia e da liberdade individuais possui um limite, abaixo do qual fica vilipendiado uma parte fundamental do projeto Democrático de Direito de tutela aos indivíduos em sua perspectiva atomizada.

Nessa complexidade é importante não perder de vista que se está a tratar não mais de projetos constitucionais liberal ou social em sua máxima pureza, e sob esse aspecto, não se pode falar em uma interpretação liberal ou social fragmentada da Constituição, nem tampouco em uma construção política do direito penal que esteja fundamentada nesses pré-juízos inautênticos, que não se confirmam solitariamente em relação à Constituição e aos problemas concretos.

Em suma, o ponto de partida para qualquer empreitada hermenêutica a ser feita em relação ao princípio da intervenção estatal, para fins de projeção de políticas criminais, deve considerar a positivação constitucional de direitos fundamentais individuais, não-individuais e culturais, todos coexistindo organicamente, os quais, em razão de sua própria natureza e função no Estado de Direito, reclamam um consenso hierárquico contextualizado.

\section{ALGUMAS INDICAÇÕES PARA O DEVIR DA POLÍTICA CRIMINAL NUM PAÍS EMERGENTE}

\subsection{Política sociais e prevenção da criminalidade tradicional}

Tentando especificar um pouco mais as linhas fundacionais de uma política criminal sistêmica a ser desenvolvida pelo Estado brasileiro é relevante, antes de mais nada, deixar posto que tal tarefa social deve ser projetada levando-se em consideração que a diversidade do fenômeno criminal brasileiro reclama uma distinção de políticas. Em outras palavras. A criminalidade tradicional reclama 
formas de tratamento político completamente diferentes da criminalidade contemporânea organizada.

Sob outro aspecto é necessário deixar claro que políticas criminais não implicam absolutamente em adoção de medidas restritas ao campo penal. Políticas sociais são políticas criminais muitíssimo mais eficientes que medidas penais. Nesse sentido, políticas criminais devem ser concebidas privilegiando a prevenção do delito através de políticas sociais positivas, afirmativas de minorias e de hipossuficientes economicamente, ao invés de se estruturarem, liminarmente, como políticas penais, consistentes em criminalizações, penalizações e outras alternativas, cunhadas dentro do universo de instrumentos instituídos pelo direito penal. Há um contexto histórico que está a exigir uma tutela mais efetiva a estratos débeis, social e economicamente, da população, pois é neles que se verifica a ebulição da maior parte do fenômeno criminal, especialmente em relação à criminalidade tradicional. Nesse sentido, impõe-se a utilização das palavras de Wacqant, para quem:

[...] a urgência, no Brasil como na maioria dos países do planeta, é lutar em todas as direções não contra os criminosos, mas contra a pobreza e a desigualdade, isto é, contra a insegurança social que, em todo lugar, impele ao crime e normatiza a economia informal de predação que alimenta a violência. ${ }^{6}$

Em termos de políticas sociais de prevenção, Molina refere-se a oito alternativas de programas como alternativas políticas adequadas ao modelo de Estado Democrático e Social de Direito, a saber: programas de "área geográfica", programas baseados no desenho arquitetônico e urbanístico, dirigidos à remodelação da convivência urbana, programas de prevenção comunitária, programas de prevenção vitimal, programas de inspiração político-social, programas orientados à reflexão axiológica, programas de orientação cognitiva e programas de prevenção da reincidência? .

Inobstante a cientificidade de todos os modelos preventivos apontados pelo catedrático da Universidade Complutense, face à emergência dos problemas socioeconômicos no Brasil e aos reflexos dessa realidade no fenômeno criminal, uma dessas possibilidades surge como prioritária: os programas de inspiração político-social.

Concordando com os liberais, é preciso ratificar a tese de que o direito penal mínimo se constitui em um ideal a ser atingido no processo civilizatório e de que os mecanismos de repressão ao crime instituídos na modernidade, particularmente as penas privativas de liberdade, não realiza(ra)m de forma alguma as finalidades de prevenção a que historicamente se propuseram. Mas a minimização do direito penal, legitimada por um consenso social, somente será viável e assimilada culturalmente pela sociedade, se ocorrer numa razão proporcional à diminuição do conflitos sociais, que geram os tipos de condutas que são qualificadas pelo direito positivo como delituosas. Assim, uma diminuição dos conflitos sociais, importando em diminuição da delinquência, legitimará uma redução dos mecanismos penais de repressão ao crime.

Sabe-se que boa parte da criminalidade que atinge uma sociedade tem suas raízes nos conflitos, que ocorrem no seio dessa mesma sociedade. São situações 
de carência quanto às necessidades fundamentais, desigualdades enormes, desacordos sociais imensos. Uma política social efetiva e contundente converte-se, assim, com certeza, no melhor instrumento preventivo da criminalidade, já que incide diretamente sobre as causas fundantes dos problemas dos quais o crime é uma consequência, uma patologia. Programas dessa natureza são, segundo a orientação de Molina, programas de prevenção primária: genuína e autêntica prevenção, pois se cada sociedade tem o crime que merece, uma sociedade mais justa, que assegure a todos os seus membros um acesso efetivo a cotas satisfatórias de bemestar e qualidade de vida - em seus mais diversos âmbitos - reduz correlativamente suas conflitividades e as suas taxas de delinquência ${ }^{8}$. E assim o faz do modo mais justo e racional, harmonizando a máxima efetividade com o menor custo social.

A premissa teórica dos programas de prevenção é muito simples: se o crime tem sua origem no abismo social que separa os indivíduos das classes e estratos mais oprimidos econômica e socialmente do projeto de bem-estar presente no texto constitucional, e esse é exatamente o principal fator determinante da criminalidade tradicional no Brasil, cabe ao Estado ou à comunidade promover alternativas eficazes, consistentes no oferecimento, aos que vivem sob tais condições, de oportunidades de serem incluídos no bem-estar social. Há a necessidade de reconectar definitivamente a questão criminal - e as possibilidades efetivas de enfrentamento do fenômeno - com a questão social, premissa que foi completamente esquecida pela dogmática, ao privilegiar um purismo metodológico orientado a uma assepsia científica do direito penal. $O$ grave em tudo isto é que variados outros ramos do conhecimento da área das ciências sociais - a sociologia, a ciência política, a psicologia etc. -, diferentemente da maior parte da dogmática penal, têm presente, de forma clara e precisa, esta ligação no centro de suas construções teóricas.

Nessa perspectiva, uma aplicação dos postulados da tradição liberal-iluminista, no contexto de um Estado Democrático de Direito, ainda mais quando se fala de um país emergente como o Brasil - constitui-se em um paradoxo, uma vez que ao propugnar uma diminuição do Estado está a defenestrar toda e qualquer possibilidade de realização de políticas públicas, instrumentos adequados para 0 enfrentamento das causas da maior parte da criminalidade contemporânea.

Assim, o caminho inexorável é a concretização de um projeto constitucionalizado de cidadania da população que se encontra mais vulnerável economicamente e, portanto, mais próxima do cometimento das condutas delituosas. E o instrumento adequado para esse fim é a efetivação de políticas públicas voltadas à concretização de direitos sociais como a educação, o trabalho, a seguridade social, a saúde, o lazer, a cultura, uma habitação digna, um salário que suporte as demandas familiares, enfim, uma série de carências que, uma vez atendidas, irão possibilitar a diminuição de grande parte da criminalidade hoje ocorrente. $\mathrm{O}$ que está em jogo, em última análise, segundo o entendimento de Wacquant:

[...] entre a edificação, por mais lenta e difícil que seja, de um Estado social, e a escalada, sem freios nem limites uma vez que se auto-alimentam, da réplica penal, é simplesmente o tipo de sociedade que o Brasil pretende construir no futuro: uma sociedade aberta e ecumênica, animada por um espírito de igualdade e concórdia, 
ou um arquipélago de ilhotas de opulência e de privilégios perdidas no seio de um oceano frio de miséria, medo e desprezo pelo outro. ${ }^{9}$

O mercado e a sociedade civil, em sua dinâmica autopoética, não cumprirão tais atribuições, pois, historicamente, o capitalismo deu mostras de sua perversão com as camadas mais desprovidas da população e de sua indiferença com políticas públicas e direitos não-individuais. Resta, então, mais uma vez, ao Estado e, por outro lado, a instituições públicas não-estatais, cumprir o papel de vetor de concretização dos interesses não-individuais e, por efeito, disso, dos próprios indivíduos atomizadamente. O inverso, que se constitui num dos fundamentos do liberalismo, de que a satisfação individual gera o bem-estar comum, não é verdadeiro, e a experiência histórica mostra isso com excessos de exemplos.

Há, em relação ao liberalismo, no que toca ao problema da intervenção estatal, um paradoxo a ser resolvido. Ao mesmo tempo que se quer o liberalismo, também não se quer. Em outras palavras: se, por um lado, se deseja o liberalismo penal no que tange ao seu sistema principiológico de garantias do indivíduo em relação aos exageros de um Estado repressor, por outro, há, por seus postulados econômicos, um total desprezo, pois é preciso reconhecer que a sua concretização mercadológica e capitalista constitui-se em grande foco de criminalidade, em decorrência da desigualdade social gerada.

As políticas públicas não-liberais funcionam, assim, num Estado Democrático de Direito, como autênticas políticas criminais, uma vez que reduzindo, pela satisfação das necessidades materiais, o grau de conflitividade social, estarão contribuindo para a redução da criminalidade e, por consequência, do próprio direito penal que, nessa perspectiva, vai perdendo a sua razão de ser, para as funções que a modernidade lhe atribuiu.

A fim de atingir tal intuito, a realização de políticas públicas, compreendidas na sua particularidade de políticas criminais, inserem-se no âmbito de intervenção estatal característica não de um modelo de Estado abstencionista, mas, noutro sentido, de um Estado interventor, transformador e garantidor, tanto de direitos individuais quanto de não-individuais.

\subsection{Políticas criminais não penais e Estado fiscal}

Ao estar voltado à concretização de direitos não-individuais, pelo menos num primeiro momento, pois, em última análise, mesmo os direitos não-individuais são condensados nos indivíduos, o Estado depende de receitas orçamentárias, pois diferentemente dos direitos individuais, que possuem um custo de efetivação zero ou irrisório $^{10}$, as políticas públicas, voltadas à realização de direitos não-individuais possuem um alto custo econômico.

Nessa linha de raciocínio, no momento histórico vivido pela sociedade brasileira, que tem experimentado altos índices de criminalidade tradicional, perpetrada pelas camadas mais violentadas economicamente, a realização das promessas sociais da modernidade depende da efetivação de uma política tributária adequada às demandas sociais brasileiras. Nesses moldes, uma política tributária efetiva e justa, que contemple os interesses públicos sem inviabilizar o setor 
produtivo, ao fornecer os recursos orçamentários necessários para a realização de políticas públicas, voltadas à implementação de direitos sociais, constitui-se num elemento de alta relevância no combate à criminalidade e, a posteriori, na redução do âmbito de incidência do direito penal. Voltado à realização de políticas públicas que, por consequência, têm a potencialidade de atuar no tratamento social da criminalidade, o tributo, utilizando a lição de José Casalta Nabais:

\begin{abstract}
[...] se nos apresenta como um dever fundamental, isto é, um instituto jurídico que tem a sua disciplina traçada ao mais alto nível - ao nível constitucional -, onde integra a "constituição do indivíduo". O que significa que o imposto não deve ser considerado, como foi tendência durante o século passado, mormente na Alemanha, uma simples relação de poder, em que o estado faz exigências aos seus súbditos e estes se sujeitam em consequência dessa relação. Noutros termos, o imposto não pode ser encarado, nem como um mero poder para o estado, nem simplesmente como um mero sacrifício para os cidadãos, mas antes como o contributo indispensável a uma vida em comum e próspera de todos os membros da comunidade organizada em Estado. ${ }^{11}$
\end{abstract}

Diferentemente de uma concepção do Estado fiscal numa perspectiva liberal, em que o Estado encarna o mau e a sociedade o bem, o Estado fiscal no Estado Democrático de Direito supera essa dicotomia, pois é através dele que as promessas de justiça e felicidade constitucionalizadas podem ser materializadas de forma civilizada. A relação Estado-sociedade no paradigma democrático de Direito muda sua face, pois todas as tarefas cometidas ao Estado pela dirigência constitucional encerram possibilidades de realização do bem, ou pode-se dizer o contrário quando se fala que é dever do Estado a efetivação da saúde, da educação e de inúmeros outros direitos de natureza social?

Uma política tributária forte e justa, destinada à realização de políticas públicas com um endereçamento político-criminal, precisa ser enfocada sob vários aspectos. Em primeiro lugar, não significa um aumento na carga tributária, que já é uma das maiores do mundo, mas sim, uma concretização de um projeto tributário justo, onde o dever de recolhimento tributário leve em consideração a capacidade contributiva, critério não considerado em boa parte de nosso sistema. Um projeto tributário justo se for efetivamente concretizado, possui uma boa potencialidade de solucionar uma gama enorme de problemas sociais que se constituem em causas da criminalidade.

Essa proposta também precisa ser construída, considerando-se um outro ângulo, qual seja, a importância da existência de mecanismos penais dirigidos ao combate da sonegação que, no Brasil, representa um percentual que equivale aproximadamente ao arrecadado. Não há possibilidade alguma de realização de um Estado de bem-estar social sem que haja arrecadação fiscal destinada ao seu financiamento. Se, posteriormente, cumprindo o direito tributário sua função na efetivação de um Estado de bem-estar social, houver um consenso quanto a um possível relaxamento de suas medidas sancionatórias, nada obsta que isso seja feito.

É preciso, entretanto, uma composição democrática entre as possibilidades de intervenção fiscal e a preservação de direitos individuais, ou, em sinonímia, uma justa ponderação entre o plano individual e coletivo. Nesse sentido, um bom exemplo é o caminho trilhado pela legislação tributária, onde, sem abrir mão do 
direito penal tributário, criou-se uma série de mecanismos legais que permitem ao Estado arrecadar, sem a necessidade de imposição de medidas penais já num primeiro momento da persecução, mas somente de forma subsidiária.

Anteriormente à entrada em vigência da Lei n. 9.249/95, a persecução estatal em relação a agentes realizadores de condutas previstas como ilícitos tributários, inclusive na esfera penal, podia ser concretizada através da incidência de duas redes sancionatórias distintas, componentes do sistema jurídico brasileiro, a saber: a rede administrativa e a rede penal.

Pela rede sancionatória administrativa podiam ser instaurados processos no âmbito das Secretarias das Receitas Federal e Estadual, que podiam evoluir para a propositura de ações executivas fiscais, as quais tinham por finalidade a arrecadação do tributo ou contribuição social devida, bem como a imposição de multas e outras sanções no âmbito administrativo. Já pela rede penal havia a possibilidade de instauração de ação penal pública incondicionada, visando a aplicação de sanção criminal, particularmente privação de liberdade.

As duas redes, pelas possibilidades normativas vigentes antes da Lei 9.249/95, podiam atuar concomitante e independentemente uma da outra, e gerar uma situação punitiva consistente numa dupla penalização: no âmbito administrativo, a arrecadação do tributo devido acrescido das multas e outros consectários decorrentes do lançamento do nome do devedor nos cadastros oficiais de inadimplentes, tais como restrições de crédito, a partipações em licitações e outros certames públicos; na esfera penal, a submissão ao processo criminal - que, por si só, já se constitui em uma pena -, a possibilidade de alguma prisão cautelar, a imposição de pena definitiva privativa de liberdade, o lançamento do nome do réu no rol dos culpados, a perda da primariedade etc. Negava-se, com a ausência total de articulação entre as redes sancionatórias administrativa e penal no âmbito tributário, não só qualquer ideia de subsidiariedade do direito penal em relação aos demais ramos de regulação jurídica, mas também uma concepção mais apurada de democracia fundada em perspectiva de tolerância e de dignidade humana.

Nesse cenário de regulação, definiam-se não só as possibilidades sancionatórias elencadas nesses dois âmbitos normativos, mas, antes disso, a própria legitimidade do Estado em atuar na persecução desse tipo de condutas e, como consequência, a função da sanção criminal num determinado projeto de sociedade, Estado e Direito. Claramente optava-se por um Estado repressor, cuja justificação de sua atuação persecutória residia não só na arrecadação de tributos, mas, também na ideia de retribuição e prevenção dos ilícitos tributários.

Com a entrada em vigência da Lei n. 9.249/95, a situação mudou significativamente, tendo essa lei redefinido os objetivos do Estado em relação ao problema tributário, à atuação estatal persecutória e à própria função da pena. Se antes dessa lei, a possibilidade de atuação concomitante e independente das duas redes sancionatórias deixava margem para compreender-se a intervenção estatal a partir de uma funcionalidade retributiva, prevencionista e arrecadatória, com a edição do referido diploma legal tributário o papel do Estado em relação às condutas lesivas à ordem tributária passou a ser preferencialmente arrecadatória, ficando as finalidades retributivas e prevencionistas em plano secundário. 
Por esta lei, através de seu artigo 34, introduziu-se no âmbito normativo tributário uma cláusula de comunicabilidade entre as redes sancionatórias administrativa e penal, de forma que o pagamento do tributo ou da contribuição social devidos, inclusive acessórios, antes do recebimento da denúncia, na esfera administrativa, extinguia a punibilidade em sede penal. Era um primeiro movimento político-legislativo no sentido de articular o funcionamento das redes sancionatórias que incidiam sobre fatos definidos como ilícitos penais e que também sofriam a incidência da rede administrativa.

Tal direcionamento político-legal consolidou-se com a instituição pela, Lei $\mathrm{n}$. $10.684 / 03$, de medidas que possibilitam o parcelamento dos débitos junto à Secretaria da Receita Federal ou à Procuradoria-Geral da Fazenda Nacional em até cento e oitenta prestações mensais e sucessivas, bem como a suspensão da pretensão punitiva do Estado, referente aos crimes previstos nos arts. $1^{\circ}$ e $2^{\circ}$, da lei n. 8.137/90 e nos arts. 168 A e 337 A, ambos do Código Penal, enquanto estiver em curso o parcelamento.

Também pela Lei n. 9.430/96, em seu artigo 83, definiu-se a necessidade de exaurimento da esfera de persecução administrativa como condição de procedibilidade para ação penal fiscal.

Há, assim, a partir da Leis n. 9.430/96 e 10.684/03, uma redefinição paradigmática do direito penal tributário que vai no sentido de um projeto no qual privilegiou-se o princípio da subsidiariedade, sem olvidar a necessidade de manutenção das possibilidades de persecução penal. Redefiniu-se, dessa forma, os objetivos do direito penal tributário, no sentido de que se deve privilegiar a arrecadação em detrimento da retribuição.

\subsection{As políticas criminais adequadas à criminalidade organizada e contra o Estado}

Sem embargo, não é possível deixar de afirmar que o direito penal, com todo o seu instrumental institucional moderno, ainda possui um importante papel nas sociedades contemporâneas. Em primeiro lugar, numa perspectiva subsidiária, funciona como uma última reserva sancionatória na hipótese de falha ou insucesso de todas as outras, para a solução de conflitos sociais que se insiram na esfera do que hoje se denomina direito penal. Neste aspecto é de ser ressaltada a função simbólica do direito penal como instrumento de expressão de uma não aceitação e reação social a determinados tipos de conduta. Nesse âmbito não resta qualquer dúvida de que um direito penal efetivo deva ser mantido para a punição de condutas atentatórias à pessoa humana e a qualquer outra espécie de condutas que sirvam como meio de realização da violência contra os indivíduos (por exemplo, tráfico de pessoas, de armas, de entorpecentes, inobstante a posição do autor em relação a este último ir no sentido de que deva haver uma descriminalização o mais ampla possível conjugada com uma forte política educacional em diversos níveis).

Em segundo lugar, o direito penal possui uma função simbólica de garantia positiva para a efetivação das políticas sociais. Se o processo de captação de recursos pelo Estado junto à sociedade é um polo extremamente importante para a 
realização de um Estado Social, também não pode ser esquecida pelo Direito a regulação da marcha de reinvestimento na sociedade dos valores arrecadados. Nesse sentido, um outro aspecto dessa política criminal, que necessariamente precisa estar agregado ao viés tributário, é a rigorização do tratamento penal aos crimes realizados contra o Estado, especialmente aqueles que se materializem através de condutas lesivas ao erário público. Isso se justifica em função do alto índice de ocorrência de crimes dessa natureza na atualidade e, por outro lado, em decorrência de inúmeras situações de impunidade ou de permanência do prejuízo aos cofres públicos, mesmo após a extinção da pena, pelo seu cumprimento, por parte dos poucos indivíduos condenados por práticas de tais crimes.

A ocorrência dessas situações de inefetividade da ação estatal na persecução e/ou punição dos crimes contra o Estado e contra o patrimônio público, por serem eles realizados geralmente por agentes públicos detentores do poder, tem gerado uma situação de descrença total da população em relação ao sistema penal no País. Isso leva a um esfacelamento do sentimento de pertencimento dos indivíduos à sociedade organizada e, evolutivamente, a uma perda da identidade dos cidadãos em relação ao Estado, retornando ao imaginário social a percepção liberalindividualista de que o Estado é o vilão e a sociedade civil a vítima.

Assim, um segundo grande pilar de uma estruturação principiológica políticocriminal vai no sentido de que o direito penal deve ser contundentemente efetivo no combate à criminalidade contra o Estado, tanto para garantir a efetividade de políticas fiscais arrecadatórias, quanto, principalmente, para garantir a concretização dos investimentos estatais em políticas sociais voltadas à realização da cidadania em seus múltiplos aspectos. Esta é uma receita política que tem sido executada há longa data por países do norte do planeta, tais como Suécia, Dinamarca, Noruega e outros, e os resultados têm sido inquestionáveis, particularmente no que tange à prevenção da criminalidade pela constituição de um Estado de Bem-Estar Social.

O entendimento de que o Estado, ao decidir incriminar uma conduta, definitivamente está a reconhecer a falência de sua política social, conforme o entendimento de Malarée, não pode ser compreendido apenas por seu aspecto negativo ${ }^{12}$. Algo de proveitoso pode nisso ser observado, uma vez que também é possível considerar que o Estado, diante de um obstáculo para a efetivação de uma política social, tendo já utilizado vários instrumentos que se mostraram ineficazes, lance mão do direito penal como elemento de intervenção. É o caso, no Brasil, por exemplo, do direito penal tributário, do direito penal econômico e do direito penal ambiental que, mesmo constituindo um arsenal normativo de repressão a condutas que violem bens dessa natureza e de garantia de arrecadação pelo Estado, possuem uma significativa e importante função social no cumprimento de alguns objetivos constitucionais.

\subsection{Algumas reflexões políticas no âmbito da teoria do bem jurídico penal}

Aqui também se coloca o problema do bem jurídico e o da consequente materialização no Estado Democrático de Direito, assim como a relação direta entre materialização e grau de intervenção estatal. Se, entre os modelos estatal liberal e social puros, a materialização era indicada por lógicas individuais-abstencionistas e coletivas-intervencionistas respectivamente, no Estado Democrático de Direito, 
diante da complexidade ôntica, presente na Constituição, pela coexistência dessas duas lógicas, o processo de materialização do bem jurídico reclama uma sofisticação maior do processo hermenêutico, que deve ser engendrado a partir dessa complexidade para definir o grau de intervenção estatal.

A análise dos indícios formais axiológico-normativos constitucionalizados revela uma tendência de ampliação da esfera de intervenção estatal, tanto penal quanto não-penal, não só pela recorrente presença de indicações ampliadoras do direito penal manifestamente expressas na Carta Magna ${ }^{13}$, mas também pela ampliação de rol de bens que foram elevados ao patamar constitucional e que, em razão disso, podem e devem, com legitimação constitucional, ser tutelados ${ }^{14}$.

Está suficientemente indicada, no texto constitucional, a necessidade de intervenção estatal para a realização dos objetivos que se orientam para a construção de uma sociedade livre, justa e solidária. A positivação do conteúdo presente no artigo $3^{\circ}$ revela o reconhecimento legal de que a situação da sociedade brasileira é de injustiça social, marcadamente pela pobreza e pelas desigualdades materiais, que fazem do Brasil um dos países, no mundo, com uma das mais complexas sociedades. O inciso primeiro desse dispositivo é a melhor expressão do reconhecimento constitucional do grave quadro social contemporaneamente atravessado. Ao ser utilizado o verbo "construir" na expressão ali contida, há, manifestamente, a identificação da situação da sociedade brasileira e a projeção da atuação do Estado para modificá-la. Há ali o reconhecimento de uma função estatal transformadora.

Se assim não fosse, se a sociedade brasileira fosse justa e solidária, sem a necessidade de sua transformação nesse sentido, provavelmente, o verbo utilizado seria manter, ou prosseguir ou qualquer outro que indicasse um caminho de conservação. Mas não é essa a realidade como a qual o Estado tem de interagir. A sociedade a ser transformada possui um enorme contingente de miseráveis, analfabetos, excluídos, que não podem ficar suscetíveis aos movimentos e idiossincrasias do mercado, sem qualquer intervenção estatal.

Sob o aspecto concreto da realidade, o grau de conflitividade social e o alto índice de carências sociais que constituem o atual momento brasileiro exigem uma efetiva intervenção estatal, e não há motivos para a exclusão liminar e absoluta do direito penal do rol de instrumentos que possam garantir a construção dessa sociedade justa, solidária, livre da pobreza e das polarizações sociais. É, desde essa situação, que se pode identificar hoje o direito penal brasileiro como uma pauta igualitária e, para tanto, dentro das exigências específicas que se fazem imperiosas para a transformação social no Brasil, não pode ficar restrito, pela aplicação de um dogma liberal descontextualizado historicamente - um pré-juizo que não se confirma diante dos indícios constitucionais e da realidade social - a uma participação mínima nesse projeto, mas deve permitir uma intervenção minimamente necessária à realização das promessas da modernidade ainda não satisfeitas para uma grande parte dos cidadãos brasileiros.

Assim, uma intervenção estatal, constituída por uma política tributária eficaz, somada a um tratamento mais pesado aos crimes contra o Estado e o patrimônio público, junto à instituição de um rigoroso sistema de controle de aplicação das 
verbas públicas, especialmente pela vinculação de receitas, é capaz de otimizar a utilização desses recursos e levar a uma efetivação de políticas públicas que, em última instância, podem reduzir o quadro de conflitividade social e, por via de consequência, diminuir a criminalidade, facultando que, num futuro próximo, o direito penal retome o caminho em direção a um mínimo ideal.

Essa provavelmente é a melhor construção político-criminal num País emergente, que possui um dos mais avançados sistemas constitucionais de direitos fundamentais. Essa provavelmente é a melhor maneira de harmonização hermenêutica, no contexto histórico experimentado atualmente pelo Brasil em toda a sua complexidade, entre a necessidade de tutela de direitos/liberdades individuais, de redução do direito penal e de efetivação de direitos não-individuais.

Por outro lado, é preciso repensar as possibilidades de intervenção estatal no que tange à tutela de uma série de bens não-individuais, cuja proteção foi objeto de previsão legal na legislação com conteúdo penal pós-Constituição de 1988. Diante das inúmeras alternativas às penas privativas de liberdade possíveis, talvez seja necessário repensar toda essa estratégia normativa. Se é para instituir-se um direito penal de tutela a esses bens, que essa tutela seja efetiva. Caso contrário, talvez seja melhor a instituição de outros mecanismos de proteção jurídica desses bens, de natureza não-penal, porque a existência de um direito penal que não se efetiva como tal, por via de sanções tipicamente penais, contribui para a proliferação de uma cultura da impunidade, de descrença no sistema penal e de liquidação de qualquer resquício de potencial preventivo em relação a essa parcela do sistema normativo penal, voltado à tutela de bens não-individuais.

Buscando resguardar a efetividade do sistema penal e as consequências disso no imaginário social, é recomendável e necessário um duplo tratamento para a criminalidade, tal como preconizado por Gonzalez de la Vega, para quem, nos casos de delitos menores, se recomenda a descriminlização, enquanto que para as mais graves infrações ou aquelas emergentes em determinadas sociedades, recomendase a criminalização, sem incorrer na viciada prática de legislações emergentes de pânico institucional ${ }^{15}$. No estrito caso brasileiro, é preciso analisar, com mais profundidade, os efeitos da edição de normas incriminadoras sem qualquer potencial de efetividade penal, tais como grande parte das que compõem o conjunto normativo incriminador pós-Constituição de 1988 e também do restante do sistema normativo penal, pois as consequências disso são, unicamente, o aumento do descrédito em relação a um sistema que já se encontra em profunda crise de efetividade.

Todas essas vicissitudes de uma política criminal adequada constitucionalmente não podem jamais perder de vista o fato de que não há liberdade de conformação do legislador contra as normas constitucionais nem discricionairiedade na não-atuação da lei fundamental. Nas palavras de Canotilho:

Se a actividade juridicamente relevante do legislador não se mover no âmbito da vinculação jurídico-material do poder legiferante e se não observar os preceitos hierarquicamente superiores da constituição, se adistinção formal e matrial entre constituição e lei (poder constituinte e constituído) se tornar de novo claudicante, a consequência será reintrodução da teoria positivista weimariana do "poder legislativo 
ordinário" em que a constituição não se situa sobre o legislador mas à sua disposição. $^{16}$

Dessa forma, não restam muitos outros caminhos para o desenvolvimento de uma política criminal senão o da adequação constitucional, tanto no âmbito da execução de políticas públicas quanto no âmbito da normatização de condutas, pois não são as políticas e as legislações que conformam a Constituição, mas a Constituição que as conforma, uma vez que uma Constituição dirigente coloca um problema fundamental: o da adequação substancial das relações materiais entre a atuação do Estado por qualquer de seus poderes e a Constituição e a lei ${ }^{17}$.

\section{PUBLIC POLITICALS AND TREATMENT OF THE CRIMNALITY IN A DEMOCRATIC SOCIETY}

\section{ABSTRACT}

The presente article intents to establish some indicative political basis that can be considered State democratic intervention, suitable to a emergent country, to face up the criminality problem, from the constitutional society project, State and Law approved in 1988.

Keywords: Constitution. Criminal prevention. Democracy. Democratic rule of law. Public Politicals.

\section{NOTAS}

1 Mestre e Doutor em Direito Público pela UNISINOS. Coordenador Executivo e Professor do Programa de Pós-Graduação em Direito, nível de mestrado da URI/Santo Ângelo. Professor do Curso de Graduação em Direito da UNICRUZ. Advogado criminalista. Professor do Mestrado e Doutorado em Direito da Universidade do Vale do Rio dos Sinos. E-mail: andre.co.petti@hotmail.com. Endereço: Universidade do Vale do Rio dos Sinos - Direito, Av. Unisinos, 9540 - Cristo Rei - CEP 93022000 - São Leopoldo, RS - Brasil - Caixa Postal: 275.

2 Cfe. CANOTILHO, josé Joaquim Gomes. Constituição Dirigente e Vinculação do Legislador. p. 365.

3 Cfe. STRECK, Lenio Luiz. Da proibição de excesso (Ubermassverbot) à proibição de proteção deficiente (Untermassverbot): de como não há blindagem contra normas penais inconstitucionais. p. 250.

4 Cfe. MOLINA, Antonio Garcia-Pablos. Tratado de Criminología. Valencia: Tirant lo blanch, 1999, p. 909-10.

5 BENDA, Ernesto et al. Manual de Derecho Constitucional. 2. ed. Marcial Pons: Madrid, 2001, p. 544.

6 Cfe. WACQUANT, Loïc. As Prisões da Miséria. Rio de Janeiro: Jorge Zahar, 2001, p. 12. Ver a respeito MOLINA, Antonio Garcia-Pablos. Tratado de Criminologia. p. 910-29.

Cfe. MOLINA, Antonio Garcia-Pablos. Tratado de Criminologia. p. 921.

Cfe. WACQUANT, Loïc. As Prisões da Miséria. p. 13.

É preciso pontuar que esta problemática do custo de realização dos direitos individuais não pode ser entendida de forma absoluta. Há direitos individuais, como por exemplo, a segurança pública, possuem um alto custo para a sua efetivação, maior, em muitos casos, que muitos direitos nãoindividuais. Entretanto, a maioria dos direitos individuais, por reclamar apenas uma abstenção erga omnes, possui, a priori, custo baixíssimo. 
Cfe. NABAIS, José Casalta. O dever Fundamental de Pagar Impostos. Coimbra: Almedina, 1998, p. 185.

12 Ver a respeito MALARÉE, Hernán Hormazábal. Política Penal en el Estado Democrático. p. 155.

13 Basta ver, por exemplo, nesse sentido, as disposições contidas nos seguintes incisos do art. 5으, da CF/88: XLI (prevê punição a qualquer discriminação atentatória dos direitos e liberdade fundamentais); XLII (prevê a criminalização do racismo e veda a fiança e a prescrição a este crime); XLIII (dispõe sobre a inafiançabilidade e insuscetibilidade de graça ou anistia a uma série de crimes); XLIV (prevê a inafiançabilidade e a imprescritibilidade de crime de ação de grupos armados, civis e militares, contra a ordem constitucional e o Estado Democrático). Também a disposição constante no $\S 3^{\circ}$, do artigo 225 , que prevê a criminalização e a penalização das condutas lesivas ao meio ambiente, enquadra-se nesse grupo de indicações constitucionais criminalizadoras e ampliadoras da intervenção estatal penal.

14 A Constituição Federal de 1988 ampliou significativamente o rol de bens elevados a tal categoria em relação aos textos constitucionais anteriores, especialmente no referente à ordem social, o qual praticamente somente abriga disposições tutelares de bens não-individuais. A simples positivação de tais valores indica senão a imposição de proteção penal, pelo menos a possibilidade de extensão do sistema penal para a guarida de tais bens. Disso resulta, sem dúvida, um deslocamento histórico do princípio da intervenção estatal penal de uma posição de minimalista para uma situação de adequação de sua magnitude numa relação direta com a gama de bens constitucionalizados, merecedores de tutela jurídica.

15 Cfe. VEGA, Rene Gonzalez de la. Política Criminológica Mexicana. México D. F.: Porrúa/Universidad Autónoma de México, 1993, p. 210.

16 Cfe. CANOTILHO, José Joaquim Gomes. Constituição Dirigente e Vinculação do Legislador, p. 63.

17 Idem, pp. 62-63.

\section{REFERÊNCIAS}

ANDRADE VIEIRA, José Carlos. Os direitos fundamentais na Constituição Portuguesa de 1976. Coimbra: Almedina, 1998.

BENDA, Ernesto et al. Manual de Derecho Constitucional. 2. ed. Marcial Pons: Madrid, 2001.

BUSTOS RAMÍREZ, Juan. Consideraciones en torno del injusto. In: Bases críticasde un nuevo derecho penal. Bogotá: Temis, 1982.

CANOTILHO, José Joaquim Gomes. Constituição Dirigente e Vinculação do Legislador. Coimbra: Coimbra, 1994.

COPETTI, André. Direito Penal e Democracia: perspectivas para efetivação democrática através do sistema punitivo. Porto Alegre: IHJ, 2006.

DUMONT, Louis. Ensaios sobre o individualismo. Uma perspectiva antropológica sobre a ideologia moderna. Lisboa: Publicações Dom Quixote, 1992.

FERRAJOLI, Luigi. Stato Sociale e Stato de Dirittto. In: Política del Diritto. Roma, 1982. v. 1.

FORSTHOFF. E. Concepto y esencia del Estado Social de Derecho. In: El Estado Social. Madrid: Centro de Estudios Constitucionales, 1986. 
GAVARA DE CARA, Juan Carlos. Derechos fundamentales e desarollo legislativo. Madrid: Centro de Estudios Constitucionales, 1994.

LASKI, Harold J. O Liberalismo europeu. São Paulo: Mestre Jou, 1973.

LOPES, Ana Maria D’Ávila. Os direitos fundamentais como limites ao poder de legislar. Porto Alegre: SAFE, 2001.

MOLINA, Antonio Garcia-Pablos. Tratado de Criminología. Valencia: Tirant lo blanch, 1999.

MALARÉE, Hernán Hormazábal. Política Penal en el Estado Democrático. In: El Poder Penal del Estado. Buenos Aires: De Palma, 1984.

MIR PUIG, Santiago. El Derecho penal em el Estado social y democrático de derecho. Barcelona: Ariel, 1994.

NABAIS, José Casalta. O dever Fundamental de Pagar Impostos. Coimbra: Almedina, 1998.

STRECK, Lenio Luiz. Da proibição de excesso (ubermassverbot) à proibição de proteção deficiente (untermassverbot): de como não há blindagem contra normas penais inconstitucionais. In: Revista do Instituto de Hermenêutica. Porto Alegre: IHJ, 2003.

PEÑA FREIRE, Antonio Manuel. La garantia em el Estado constitucional de derecho. Madrid; Trotta, 1997.

PÉREZ LUÑO, Antonio-Enrique. Derechos Humanos y Constitucionalismo en la Actualidad. In: (coord.). Derechos Humanos e constitucionalismo ante el tercer milenio. Madrid: Marcial Pons, 1996.

REALE, Miguel. O Estado Democrático de Direito e o Conflito de Ideologias. São Paulo: Saraiva, 1998.

VEGA, Rene Gonzalez de la. Política Criminológica Mexicana. México D. F.: Porrúa/Universidad Autónoma de México, 1993.

WACQUANT, Loïc. As Prisões da Miséria. Rio de Janeiro: Jorge Zahar, 2001.

ZAFFARONI, Raul Eugenio. Em busca das penas perdidas. Rio de Janeiro: Revan, 1983.

Recebido para publicação: 19/04/2010

Aceito para publicação: 27/12/2010 